\title{
Study of antepartum haemorrhage and its maternal and perinatal outcome
}

\author{
Priyanka Tyagi*, Nidhi Yadav, Parul Sinha, Uma Gupta
}

Department of Obstetrics and Gynaecology, Era's Lucknow Medical College and hospital, Lucknow, Uttar Pradesh, India

Received: 09 September 2016

Accepted: 05 October 2016

\section{*Correspondence:}

Dr. Priyanka Tyagi,

E-mail: priyankayagi10@gmail.com

Copyright: () the author(s), publisher and licensee Medip Academy. This is an open-access article distributed under the terms of the Creative Commons Attribution Non-Commercial License, which permits unrestricted non-commercial use, distribution, and reproduction in any medium, provided the original work is properly cited.

\section{ABSTRACT}

Background: Antepartum haemorrhage (APH) is defined as bleeding from or into the genital tract after the period of viability until delivery of fetus. Etiology includes placenta previa, abruptio placentae, local causes, systemic causes and idiopathic origin. Objective of this study was to identify factors associated with APH, and to quantitate maternal morbidity, mortality and perinatal outcome in patients with APH at a tertiary care center in India.

Methods: The study was a retrospective observational study and patient information was obtained from delivery records of 100 women presenting at gestational age of 28 weeks and above with APH. All patients with bleeding per vagina after 28 weeks of gestation were included in the study and were grouped as - Placenta Previa (PP), Abruptio Placenta (AP) or unknown causes.

Results: Out of total 100 cases of APH, placenta previa contributed to 80\%, abruptio placenta $19 \%$ and $1 \%$ unknown causes. Overall maternal mortality was $6 \%$. Perinatal mortality was $42 \%$. Prevalence of low birth weight and preterm babies was high.

Conclusions: APH is a major cause of maternal and perinatal morbidity and mortality which could be prevented by early registration, regular antenatal care, early detection of high risk cases, and early referral to higher center. Good facilities for caesarean section, availability of blood banks and multidisciplinary approach with a good NICU can improve maternal and perinatal outcome of APH. The results of this study were found in good agreement with previous studies.

Keywords: Antepartum hemorrhage, Abruptio placenta, APH, Placenta previa

\section{INTRODUCTION}

Antepartum haemorrhage (APH) is defined as bleeding from or into the genital tract after the period of viability until delivery of fetus. The World Health Authority defines antepartum haemorrhage as bleeding after 28th week of pregnancy. ${ }^{1}$ On an average 2 to $5 \%$ of all pregnancies are complicated by antepartum haemorrhage. ${ }^{1,2}$ Obstetric haemorrhage accounts for 22$25 \%$ of maternal mortality and amongst these antepartum haemorrhage is the most common cause of morbidity and mortality accounting for half of these deaths. ${ }^{2}$ Etiology includes placenta previa, abruptio placentae, local causes, systemic causes and idiopathic origin.

Placenta previa refers to a placenta situated partially or completely within the lower uterine segment. Incidence is 4-5 per 1000 pregnancies.

Placenta previa is classified as: ${ }^{1}$

- Type 1 or Low lying: Encroaches lower uterine segment but does not reach internal os 
- $\quad$ Type 2 or Marginal: Reaches margin of the internal os but does not cover it.

- Type 3 or Partial: Partially covers the internal os.

- Type 4 or Total or Central: Completely covers the internal os.

The etiology of placenta previa remains controversial. The major theories focus on endometrial damage in the corpus and defective genetics or placental mechanism. In humans the blastocyst is completely embedded in the substance of endometrium so abnormalities of endometrial vascularization, delayed ovulation, and prior trauma to the endometrium appear to influence the site of implantation, therefore contributing to the probability of Placenta Previa.,

A number of studies have established its association with $^{6,9}$ :

- Advanced maternal age ( $>40$ years)

- Multiparity

- Previous placenta previa

- Deficient endometrium due to presence or history of: uterine scar (previous caesarean section, pregnancy termination followed by curettage), endometritis, manual removal of placenta, or submucous fibroid

- Multiple pregnancy

- Smoking

Placental abruption is the separation of placenta either partially or totally from its implantation site before delivery. It is initiated by haemorrhage into the decidua basalis which results in retroplacental hematoma. The phenomenon of impaired trophoblastic invasion with subsequent atherosis is related and inflammation or infection may also be contributory. ${ }^{1}$

Risk factors for placental abruption include advanced maternal age, multiparity, low body mass index (BMI), abruption in a previous pregnancy, pre-eclampsia, polyhydramnios, intrauterine infection, premature rupture of membranes, abdominal trauma, smoking, drug misuse (cocaine and amphetamines), pregnancy following assisted reproductive techniques and maternal thrombophilias. ${ }^{9}$

Objective of this study was to identify factors associated with antepartum haemorrhage, and to quantitate maternal morbidity, mortality and perinatal outcome in patients with APH at a tertiary care center in Lucknow, India.

\section{METHODS}

A retrospective observational study was carried out at Era's Lucknow Medical College and hospital, Lucknow. Patient information was obtained from delivery records of 100 women presenting at gestational age of 28 weeks and above with antepartum haemorrhage.
All patients with bleeding per vaginum after 28 weeks of gestation were included in the study. Diagnosis was made on the basis of history, clinical examination and ultrasound findings and cases were grouped as - Placenta Previa (PP), Abruptio Placenta (AP) or other causes. Analysis was done using Microsoft Excel 2013.

\section{RESULTS}

Hundred patients with APH were analysed which included $80 \%$ cases of PP, $19 \%$ cases of AP and $1 \%$ with unknown cause.

Table 1: Demographic distribution of cases $(n=100)$.

\begin{tabular}{|c|c|c|c|}
\hline & & \multicolumn{2}{|c|}{ No of patients } \\
\hline & & $\begin{array}{l}\text { Placenta } \\
\text { previa }\end{array}$ & $\begin{array}{l}\text { Abruptio } \\
\text { placenta }\end{array}$ \\
\hline \multirow{5}{*}{$\begin{array}{l}\text { Age } \\
\text { distribution }\end{array}$} & $<20$ years & 0 & \\
\hline & $21-25$ years & 0 & \\
\hline & $26-30$ years & 61 & \\
\hline & $31-35$ years & 32 & \\
\hline & $>35$ years & 7 & \\
\hline \multirow{5}{*}{$\begin{array}{l}\text { Gravida } \\
\text { distribution }\end{array}$} & Primi & 48 & 3 \\
\hline & Gravida 2 & 25 & 5 \\
\hline & Gravida 3 & 4 & 0 \\
\hline & Gravida 4 & 2 & 11 \\
\hline & $\begin{array}{l}\text { Gravida } 5 \text { or } \\
\text { more }\end{array}$ & 1 & 0 \\
\hline \multirow{2}{*}{$\begin{array}{l}\text { Booked or } \\
\text { unbooked }\end{array}$} & Booked & 34 & 0 \\
\hline & Unbooked & 46 & 19 \\
\hline
\end{tabular}

Majority of patients were in the age group of 26-30 years (61\%) (Table 1). In patients with PP, 60\% were primigravida while AP was more common in multigravida with $58 \%$ (11 out of 19) seen in gravida 4 (Table 1).

Rural background was predominant with $92 \%$ of APH patients having primary residence in rural area. Only $10 \%$ of PP patients and none of AP patients were from urban area.

$66 \%$ of APH patients were unbooked $(57.5 \%$ cases of placenta previa and $100 \%$ cases of abruptio placenta) (Table 1).

Majority of the APH patients belonged to class 4 and 5 of Modified Kuppuswamy Prasad's classification.

$5 \%(\mathrm{~N}=4)$ patients of PP had associated twin pregnancy. (Table 2)

$25 \%$ cases of PP had associated malpresentation while $84 \%$ cases of AP were associated with pre-eclampsiaeclampsia syndrome (Table 2).

Previous LSCS scar was present in $33.75 \%$ of PP patients $(n=27)$ while $6.25 \%$ cases $(n=5)$ of PP had prior history 
of $\mathrm{D}$ and $\mathrm{C}$ (Table 3). Incidence of placenta accrete syndrome in scarred uterus was found to be $6.25 \%$ (2 out of 32 cases) in our study.

Gestational age at termination was less than 37 weeks in $38 \%$ cases of APH. $28 \%$ pregnancies were terminated between 28 to 32 weeks, $9 \%$ at 32.1 weeks to 34 weeks and only $1 \%$ between 34 to 36.6 weeks (Table 4 ).

Table 2: Associated risk factor.

\begin{tabular}{|lll|}
\hline & $\begin{array}{l}\text { Placenta } \\
\text { previa }\end{array}$ & $\begin{array}{l}\text { Abruptio } \\
\text { placenta }\end{array}$ \\
\hline Malpresentation & 20 & 0 \\
\hline PIH & 0 & 11 \\
\hline Eclampsia & 2 & 5 \\
\hline Oligohydraminos & 3 & 0 \\
\hline $\begin{array}{l}\text { Multiple } \\
\text { Pregnancy }\end{array}$ & 4 & 0 \\
\hline
\end{tabular}

Mode of delivery in $89 \%$ cases of APH was LSCS while vaginal delivery was seen in $11 \%$ of cases. In patients that had PP, $98.75 \%$ (79 out of 80 ) had LSCS and only 1 had FTNVD while $47.4 \%$ cases of AP had LSCS and $52.6 \%$ had vaginal delivery (Table 5).

Table 3: Distribution of patients according to previous scar.

\begin{tabular}{|lll|}
\hline & $\begin{array}{l}\text { Placenta } \\
\text { Previa }\end{array}$ & $\begin{array}{l}\text { Abruptio } \\
\text { placenta }\end{array}$ \\
\hline Previous LSCS & 27 & 0 \\
\hline D and C & 5 & 11 \\
\hline Any other scar & 0 & 0 \\
\hline
\end{tabular}

PPH was a major intrapartum complication involving $45 \%$ cases of APH. $42.5 \%$ cases of PP (34 out of 80 ) had PPH during delivery with per operative finding of one case each of focal placenta accreta, placenta increta and bicornuate uterus (Table 6).

Table 4: Distribution of patients according to gestational age at termination.

\begin{tabular}{|llll|}
\hline & $\begin{array}{l}\text { Placenta } \\
\text { previa }\end{array}$ & $\begin{array}{l}\text { Abruptio } \\
\text { placenta }\end{array}$ & Unclassified \\
\hline $\begin{array}{l}\text { 28-32 } \\
\text { weeks }\end{array}$ & 25 & 2 & 1 \\
\hline $\begin{array}{l}32.1-34 \\
\text { weeks }\end{array}$ & 9 & 0 & 0 \\
\hline $\begin{array}{l}34.1- \\
\text { 36.6weeks }\end{array}$ & 1 & 0 & 0 \\
\hline
\end{tabular}

Blood transfusion was required intraoperatively in $45 \%$ of total APH patients with $42.5 \%$ of PP cases and $58 \%$ of AP cases requiring blood transfusion. Uterine tamponade was used in $31 \%$ patients of APH, $42 \%$ required uterine artery ligation and $41 \%$ had hemostatic sutures placed to control bleeding. Combination of different methods was used in many patients. However, caesarean hysterectomy was needed in $7 \%$ patients of APH with $5 \%$ (4 out of 80) cases of PP, all in cases of central placenta previa, among these one case had focal placenta accreta, one case had placenta increta and another case with bicornuate uterus and one patient died due to thromboembolism in postoperative period. $15.7 \%$ ( 3 out of 19) cases of AP had caesarean hysterectomy (Table 7).

Table 5: Mode of delivery.

\begin{tabular}{|llll|}
\hline & $\begin{array}{l}\text { Placenta } \\
\text { previa }\end{array}$ & $\begin{array}{l}\text { Abruptio } \\
\text { placenta }\end{array}$ & Unclassified \\
\hline $\begin{array}{l}\text { Emergency } \\
\text { LSCS }\end{array}$ & 79 & 9 & 1 \\
\hline FTND & 1 & 10 & 0 \\
\hline
\end{tabular}

Table 6: Intrapartum complication.

\begin{tabular}{|lll|}
\hline PPH & $\begin{array}{l}\text { Placenta } \\
\text { previa }\end{array}$ & $\begin{array}{l}\text { Abruptio } \\
\text { placenta }\end{array}$ \\
\hline $\begin{array}{l}\text { Maternal } \\
\text { collapse }\end{array}$ & 34 & 11 \\
\hline Placenta accreta & 1 & 0 \\
\hline Placenta increta & 1 & 0 \\
\hline Uterine anomaly & $\begin{array}{l}1 \text { (Bicornuate } \\
\text { uterus) }\end{array}$ & 0 \\
\hline
\end{tabular}

Post operatively, 5\% patients of APH had secondary $\mathrm{PPH}$, all in cases of placenta previa while $92 \%$ required blood transfusion in postop period $(90 \%$ of PP and $100 \%$ of AP). $25 \%$ required ICU admission with $40 \%$ of these requiring ventilator supports. $2.5 \%$ developed febrile morbidity associated with uterine packing while $7 \%$ cases landed in septicemia. Wound complications (infection, dehiscence) was noted in $3 \%$ cases of APH while systemic complications (respiratory morbidity, ARF, eclampsia) were seen in $11 \%$ (7.4\% in PP and $26 \%$ in AP). One patient of placenta previa developed thromboembolism in the post-operative period. (Table 8)

Table 7: Per operative intervention.

\begin{tabular}{|lll|}
\hline $\begin{array}{l}\text { Blood } \\
\text { transfusion }\end{array}$ & 34 & 11 \\
\hline $\begin{array}{l}\text { Uterine } \\
\text { packing }\end{array}$ & 31 & 0 \\
\hline $\begin{array}{l}\text { Caesarean } \\
\text { hysterectomy }\end{array}$ & 4 & 3 \\
\hline
\end{tabular}

Neonatal outcome overall was poor with $32 \%$ APH patients having IUD (32.5\% of PP and $26 \%$ of AP). $32 \%$ of newborns needed NICU admission, (30\% newborns of placenta previa patients and $42 \%$ newborns of abruptio placenta patients) (Table 9).

Analysis of maternal outcome revealed overall maternal mortality was $6 \%$ (6 out of 100) of all cases of APH. All 
the patients had central placenta previa giving a mortality rate of $7.5 \%$ in placenta previa patients. Perinatal mortality was $42 \%$ (40\% of PP cases and $47.3 \%$ of AP cases) (Table 10).

Table 8: Post op complication.

\begin{tabular}{|lll|}
\hline PPH & $\begin{array}{l}\text { Placenta } \\
\text { previa }\end{array}$ & $\begin{array}{l}\text { Abruptio } \\
\text { placenta }\end{array}$ \\
\hline BT & 5 & 0 \\
\hline Need for ICU & 73 & 19 \\
\hline Need for ventilator & 5 & 9 \\
\hline Sepsis & 16 & 5 \\
\hline $\begin{array}{l}\text { Wound } \\
\text { complication }\end{array}$ & 2 & 5 \\
\hline Respiratory & 2 & 0 \\
\hline Eclampsia & 2 & 0 \\
\hline ARF & 2 & 5 \\
\hline Thromboembolism & 1 & 0 \\
\hline
\end{tabular}

Table 9: Neonatal outcome.

\begin{tabular}{|llll|}
\hline & $\begin{array}{l}\text { Placenta } \\
\text { previa }\end{array}$ & $\begin{array}{l}\text { Abruptio } \\
\text { placenta }\end{array}$ & Unclassified \\
\hline IUD & 26 & 5 & 1 \\
\hline $\begin{array}{l}\text { Need for } \\
\text { NICU }\end{array}$ & 24 & 8 & 0 \\
\hline
\end{tabular}

Table 10: Maternal and perinatal mortality.

\begin{tabular}{|llll|}
\hline & $\begin{array}{l}\text { Placenta } \\
\text { previa }\end{array}$ & $\begin{array}{l}\text { Abruptio } \\
\text { placenta }\end{array}$ & Unclassified \\
\hline $\begin{array}{l}\text { Maternal } \\
\text { mortality }\end{array}$ & 6 & 0 & 0 \\
\hline $\begin{array}{l}\text { Perinatal } \\
\text { mortality }\end{array}$ & 32 & 9 & 1 \\
\hline
\end{tabular}

\section{DISCUSSION}

Incidence of APH has been quoted in other studies in the range of $2-5 \%$. $^{1,2,10,11}$

In our study majority of the cases of APH were due to placenta previa $(80 \%)$ followed by abruptio (19\%) which is similar to studies done by Maurya et al , Adekanle et al. ${ }^{10,12}$

The age distribution in our study revealed that $61 \%$ of APH cases were aged 26 -30 years which is similar to study by Adekanle et al in which $40 \%$ APH patients were between 25-29 years while in the study by Maurya et al the incidence of placenta previa was higher in 26-30 years age group. ${ }^{10,12}$

We observed more primigravida patients to have placenta previa while multiparity was more common in abruptio placenta, however, in studies by Arora et al, Pandey et al,
Maurya et al most of the patients with placenta previa were multigravida while abruptio was seen more in primigravida and low parity. ${ }^{10,12,13}$ This disparity could be probably because of more number of primigravida seen in our institute and due to increased prevalence of pelvic inflammatory diseases in low socioeconomic class of patients. In addition a majority of these patients were referred from various peripheral health centers.

Majority of APH cases in our study had a rural background with $90 \%$ of PP cases and all AP cases comprising of rural population which was in concordance with previous studies by Maurya et al and Pandey et al. $^{10,11}$

$66 \%$ cases of APH cases in our study were unbooked and reported in emergency with bleeding per vaginum or labour pains. This was similar to previous studies done by Maurya et al which reports $62 \%$ unbooked cases and same result was seen with study by Pandey et al, Adekanle et al. ${ }^{10-12}$

APH cases mostly belonged to class 4 and 5 according to Modified Kuppuswamy Prasad's classification 2013. ${ }^{10,11}$

History of previous LSCS was present in $27 \%$ of APH cases and history of $\mathrm{D}$ and $\mathrm{C}$ present in $16 \%$. Previous LSCS scar was present in $33.75 \%$ of PP cases and $6.25 \%$ had history of $\mathrm{D}$ and $\mathrm{C}$ emphasizing the increased incidence of PP in these patient groups as was also seen in studies by Sheiner et al Rasmussen et al. ${ }^{6,8}$ Incidence of placenta accrete syndrome in patients with placenta previa and scarred uterus in our study was $6.25 \%$ while the study by Nasreen et al showed the incidence of placenta accreta to be $14.2 \%$ in scarred uterus with placenta praevia. ${ }^{5}$

$25 \%$ cases of PP had associated malpresentation which is the same (25\%) as seen in study by Maurya et al, Pandey et al. ${ }^{10,11}$ Around $39 \%$ cases of PP had malpresentation in study by Nasreen et al. ${ }^{5}$ This high incidence of malpresentation also accounts for increased caesarean rate even in minor degrees of PP. 84\% case of AP were associated with pre-eclampsia-eclampsia syndrome in our study as against $67 \%$ in study by Maurya et al and $52 \%$ in study by Pandey et al. ${ }^{10,11}$

The gestational age at termination of pregnancies complicated by APH in our study was less than 37 completed weeks in $38 \%$ of APH patients, amongst these $74 \%$ were terminated between 28 to 32 weeks in maternal interest which is one of the factors accounting for high perinatal mortality of $42 \%$ in our study. $44 \%$ pregnancies with PP were terminated before 37 weeks and $10.5 \%$ patients with AP delivered before 37 weeks. Similar results were appreciated in study by Maurya et al in which $52 \%$ patients delivered before 37 weeks with majority being cases of PP. ${ }^{10} 28 \%$ premature deliveries were reported by Nasreen et al in patients with PP. ${ }^{5}$ 
In our study $89 \%$ APH cases had LSCS and $11 \%$ had vaginal delivery. $98.75 \%$ cases of PP were delivered by caesarean section and $1.25 \%$ delivered vaginally, $47.4 \%$ cases of AP had LSCS and $52.6 \%$ delivered vaginally (Table 5), which is similar to study by Maurya et al with 94.3\% LSCS rate in APH patients. ${ }^{10}$ Study by Pandey et al too reported $96 \%$ LSCS rate in PP patients. ${ }^{11}$

Caesarean hysterectomy was performed in $7 \%$ cases of APH. 5\% $(n=4)$ cases with PP had caesarean hysterectomy which is similar to incidence of $5.3 \%$ in SOGC clinical practice guidelines and $5 \%$ in study by Nasreen et al. ${ }^{5}$

In addition patients with PP and scarred uterus had a $12.5 \%$ risk of caesarean hysterectomy which is similar to risk quoted in study by Nielsen et al. ${ }^{14}$ All the 4 patients in PP group who underwent caesarean hysterectomy had central placenta previa, 3 out of 4 were unbooked, and all had preterm emergency LSCS for bleeding per vaginum. One case had focal placenta accreta, another had placenta increta, third had bicornuate uterus, all these findings were discovered per operatively. These findings prove the importance of antenatal care and prior knowledge of complicating factors since surgery planned electively with the knowledge of complicating factors leads to multidisciplinary approach and better preparedness which could have reduced the morbidity in these cases.

$15.8 \%$ (3 out of 19) cases with AP had caesarean hysterectomy, all of these patients were unbooked and all of them had associated anemia and preeclampsia, all had emergency preterm caesarean section in maternal interest or due to deteriorating condition of the mother.

Perinatal outcome was poor in AP as compared to PP, $47.3 \%$ perinatal mortality in AP as against $40 \%$ in PP. The studies done by Maurya et al Pandey et al Siddiqui et al also showed the perinatal outcome to be worse in AP patients. $^{10,11,15}$ Perinatal mortality in this study was $42 \%$ in APH comparable to $40 \%$ in study done by Nawrorji Wadia Hospital Mumbai. ${ }^{11}$ However our perinatal mortality was much higher than in other studies, this is probably due to the high number of patients referred from peripheral centers so that by the time they arrive intrauterine demise has already occurred due to heavy blood loss or severe fetal distress. ${ }^{10-12}$ Further contributing to the high mortality is the fact that $38 \%$ pregnancies had to be terminated preterm out of which $74 \%$ were terminated between 28 to 32 weeks and the survival of neonates at this gestational age in our NICU setup is poor further emphasizing the importance of multidisciplinary approach. Similar high perinatal mortality of $44 \%$ was also observed in study by Nasreen et al ${ }^{5}$ in PP patients due to poor NICU facilities.

Maternal mortality in our study was $6 \%$, all in cases of PP which is similar to study by Maurya et al. ${ }^{10} 5$ out of 6 deaths were caused by severe hemorrhage and hypovolemic shock while one patient developed thromboembolism in postoperative period.

Of these 6 patients, 4 were unbooked $(66.6 \%)$, all presented in emergency with heavy bleeding due to central placenta previa, 2 of these had severe anemia, one had severe anemia with placenta increta, 2 had twin pregnancy with anemia with eclampsia while one patient developed thromboembolism in the post-operative period.

\section{CONCLUSION}

Antepartum haemorrhage is a major cause of maternal and perinatal morbidity and mortality which could be prevented by early registration, regular antenatal care, early detection of high risk cases, and early referral to higher center. Good facilities for caesarean section, availability of blood banks and good NICU set up and multidisciplinary approach can improve maternal and perinatal outcome of APH. The results of this study were found in good agreement with previous studies.

\section{Funding: No funding sources \\ Conflict of interest: None declared \\ Ethical approval: Not required}

\section{REFERENCES}

1. Mishra R. Ian Donald's Practical Obstetric Problems. Seventh edition. LWW. 2014. pp. 315-328.

2. Bhide A, Thilaganathan B. Recent advances in the management of placenta previa. Curr Opin Obstet Gynecol. 2004;16(6):447-51.

3. Faiz AS, Ananth CV. Etiology and risk factors for placenta previa: an overview and meta-analysis of observational studies. J Matern-Fetal Neonatal Med Off J Eur Assoc Perinat Med Fed Asia Ocean Perinat Soc Int Soc Perinat Obstet. 2003;13(3):175-90.

4. Lavery JP. Placenta previa. Clin Obstet Gynecol. 1990;33(3):414-21.

5. Nasreen F. Incidence, Causes and outcome of placenta previa. J Postgrad Med Inst Peshawar - Pak. 2011.

6. Sheiner E, Shoham-Vardi I, Hallak M, Hershkowitz R, Katz M, Mazor M. Placenta previa: obstetric risk factors and pregnancy outcome. J Matern Fetal Med. 2001;10(6):414-9.

7. Healy DL, Breheny S, Halliday J, Jaques A, Rushford D, Garrett C, et al. Prevalence and risk factors for obstetric haemorrhage in 6730 singleton births after assisted reproductive technology in Victoria Australia. Hum Reprod Oxf Engl. 2010;25(1):265-74.

8. Rasmussen S, Albrechtsen S, Dalaker K. Obstetric history and the risk of placenta previa. Acta Obstet Gynecol Scand. 2000;79(6):502-7.

9. Antepartum Haemorrhage (Green-top Guideline No. 63). Royal College of Obstetricians and amp; Gynaecologists. Available from: 
https://www.rcog.org.uk/en/guidelines-researchservices/guidelines/gtg63/.

10. Maurya A, Arya S. Study of Antepartum Haemorrhage and Its Maternal and Perinatal Outcome. Int J Sci Res Publ. 2014.

11. Pandey VP, Pandey M. Study of Antepartum Haemorrhage and its Maternal and Perinatal Outcome. 2016. Available from: http: //imsear.li.mahidol.ac.th/handle/123456789/175784.

12. Adekanle DA, Adeyemi AS, Fadero FF. Antepartum haemorrhage and pregnancy outcome in Lautech teaching Hospital, southwestern Nigeria. J Med Sci. 2011:1243-7.
13. Arora R, Devi U, Majumdar K. Perinatal morbidity and mortality in antepartum haemorrhage. J Obstet Gynae India. 2001;51(3):102-4.

14. Nielsen TF, Hagberg $H$, Ljungblad U. Placenta previa and antepartum hemorrhage after previous cesarean section. Gynecol Obstet Invest. 1989;27(2):88-90.

15. Siddiqui SA, Tariq G, Soomro N, Sheikh A, Shabihul-Hasnain F, Memon KA. Perinatal outcome and near-miss morbidity between placenta previa versus abruptio placentae. J Coll Physicians Surg-Pak JCPSP. 2011;21(2):79-83.

Cite this article as: Tyagi $\mathrm{P}$, Yadav N, Sinha $\mathrm{P}$, Gupta U. Study of antepartum haemorrhage and its maternal and perinatal outcome. Int J Reprod Contracept Obstet Gynecol 2016;5:3972-7. 